\title{
Start Small, Then Achieve Big Impact
}

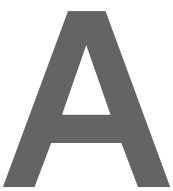

CM HAS AN amazing cadre of volunteers around the globe, and they deserve the credit for what ACM accomplishes. It's not just that volunteers are the ones who come up with innovative ideas. They also invest their personal time to make those ideas come to life. ACM owes its success to volunteers' collective efforts to "start small, but with a big vision in mind." Let's look at some recent examples.

Taking a stand on harassment. It's hard to work in computing these days and not be aware that people who are "different" feel excluded from many technical conversations and opportunities. Studies have shown that's one reason young women and people from underrepresented groups don't choose computing as a career. ACM is not directly involved in hiring or educating the future workforce, but as a professional society we can and should speak out about the importance of encouraging representation from all backgrounds, perspectives, and ideas. This is reflected in the ACM Code of Ethics and Professional Conduct (ethics.acm.org), particularly sections 1.4 and 1.5 .

What I'd like to recognize here is how the work of many volunteers contributed to what has become an ACM-wide stance on what constitutes acceptable behavior. Although we have no authority over what happens in the workplace or classroom, we can address behavior at all ACM events, from conferences to committee meetings to sponsored speaker events. ACM members noted that sometimes a speaker or attendee engages in behavior that is demeaning or offensive to other participants. Concerned volunteers began trying to codify what behavior is/isn't acceptable and what the consequences of poor behavior should be. What started as statements by specific conferences culminated in our formal Policy Against Harassment at ACM Activities (http://bit.ly/2PXiz98). This was followed by a Policy on Coercion and Abuse in the ACM Publications Process (http://bit.ly/2PWyvbY). There is more work to be done, but these policies address the most common ACM contexts.

Recognizing the need for reproducible computing. Technology has become essential to everyday life, which means society collectively places a lot of trust in technology. Since software and data reliability is key to that trust, it must be possible to independently verify the results of algorithms and software. Recently, volunteers working with a couple of ACM journals and conferences began to encourage authors to include their data, code, intermediate results, and so on as part of the publication process. These efforts A sampling of the summer/winter schools offered by ACM groups in 2019

\begin{tabular}{lcc} 
Topic & Location & ACM Group \\
\hline Detection and Analysis of Malware & Pune, India & ACM India Council \\
\hline HPC for AI and Dedicated Applications & Barcelona, Spain & ACM Europe Council \\
\hline Data Science & Athens, Greece & SIGMOD+SIGIR+SIGKDD \\
\hline Cybersecurity and Data Analytics & Delhi, India & ACM India Council \\
\hline Projects Based on UN's Sustainability Goals & Prague, Czech Rep. & SIGEVO \\
\hline Hybrid Cloud & Bangalore, India & ACM India Council \\
\hline $\begin{array}{l}\text { Machine Learning for Data Mining } \\
\text { and Search }\end{array}$ & Cape Town, S. Africa & SIGIR+SIGKDD \\
\hline
\end{tabular}

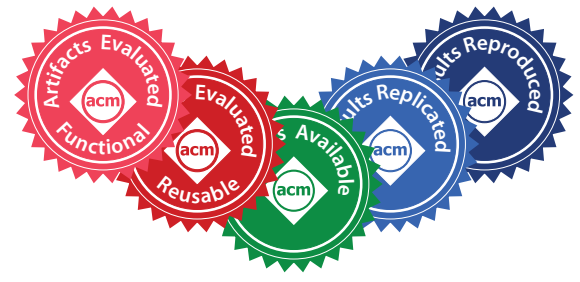

gained momentum, with some conferences even awarding prizes for cases where independent teams succeeded in reproducing the results. The ACM Digital Library now has a series of "badges" reflecting what supporting materials are available and the extent to which they have been evaluated or replicated by others (www.acm.org/ publications/artifacts). The badges are indicators of skill and quality, recognizing the extra effort required to make computing processes more transparent.

Expanding the reach of computing. Some of the most exciting work happens at the intersection of computing with other disciplines, or in areas still emerging within mainstream computer science. Each year, ACM's Special Interest Groups and regional councils host summer schools where students and researchers explore new challenges and experiment with new techniques. The table shows some of the summer/winter schools around the globe in 2019. These events create opportunities to start building a community that may result in a future publication, conference, or SIG.

These are just some of the many ways small groups within ACM share ideas that end up taking on a life of their own. Special thanks to all of you who contributed to them. And I challenge other members to reach out to your colleagues and consider developing your own grassroots effort. What's small today could be a global initiative within just a few years.

Cherri M. Pancake, ACM PRESIDENT 